\title{
Kelley and Firestein's Textbook of Rheumatology, 2-volume Set, 10th Edition
}

Gary S. Firestein, Ralph C. Budd, Sherine E. Gabriel, Iain B. McInnes, and James R. O’Dell, eds. Philadelphia: Elsevier, 2017, 2288 pages, \$585 US

Kelley and Firestein's Textbook of Rheumatology is a well-organized resource for residents and practicing rheumatologists. The first half of Volume 1 covers anatomy, immunology, as well as broad topics such as cancer risk in rheumatic diseases and pregnancy. As a trainee, I found it very helpful to have basic science concepts presented in a way that helps me understand their clinical relevance. This volume also reviews the approach to regional pain, laboratory testing, injection techniques, imaging, and pharmacology. The summary tables were very helpful to highlight key points.

Volume 2 dives into the individual rheumatic diseases with excellent clinical images. Each chapter delves into the background, pathophysiology, outcome measures, and treatment with an extensive list of resources for additional reading. Given the extent of topics covered, I found the headings to be particularly effective to narrow down the areas I wanted to review or re-read.

Kelley and Firestein's Textbook of Rheumatology is an excellent 2 -volume series that covers the spectrum of rheumatology, from understanding the molecular basis of disease to approaches to practical topics (injection techniques, imaging) to specific disease entities, both common and uncommon. I would highly recommend this book for rheumatology residents as a study resource and practicing rheumatologists as a reference book given its thorough yet succinct delivery of many topics.

STEPHANIE TOM, MD, University of Toronto Faculty of Medicine, Rheumatology, 399 Bathurst St., Toronto, Ontario M5T 2S8, Canada. E-mail: stephanietom.md@gmail.com

J Rheumatol 2017;44:6; doi:10.3899/jrheum.170289 